\title{
Gestagen treatment enhances the tocolytic effect of salmeterol in hormone-induced preterm labor in the rat in vivo
}

\author{
Márta Gálik; Róbert Gáspár, PhD; Zoltán Kolarovszki-Sipiczki, PhD; George Falkay, DSc
}

OBJECTIVE: The purpose of this study was to determine whether gestagen treatment enhances the effects of $\beta_{2}$-mimetics in hormone-induced preterm delivery in pregnant rats in vivo.

STUDY DESIGN: Preterm birth was induced with a combination of mifepristone and prostaglandin $E_{2}$ on day 19 of pregnancy. The animals were treated with salmeterol or gestagens (progesterone or $17 \alpha$ hydroxyprogesterone) or their combination. The treatments were launched on different days (15-18) of pregnancy. The efficacy of treatment was determined in terms of the delivery time counted from the mifepristone injection.
RESULTS: Salmeterol treatment delayed premature labor by 2.4 hours, whereas the delay because of the gestagen-salmeterol combinations was more than 5 hours. Progesterone had no effect on the delivery time.

CONCLUSION: Parallel treatment with salmeterol and gestagens can be more than twice as effective as salmeterol therapy alone. These results open up a possibility for human trials of combined $\beta_{2}$-agonist-gestagen therapy in threatening preterm delivery.

Key words: beta-mimetics, gestagens, preterm birth, rat, tocolysis

Cite this article as: Gálik M, Gáspár R, Kolarovszki-Sipiczki Z, et al. Gestagen treatment enhances the tocolytic effect of salmeterol in hormone-induced preterm labor in the rat in vivo. Am J Obstet Gynecol 2008;198:319.e1-319.e5.

$\mathrm{V}$ arious medications have been used in tocolytic therapy, but none have been established as effective treatment of preterm labor. Supplemental treatment with progesterone $(\mathrm{P})$ has been studied to prevent preterm labor and birth ${ }^{1-4}$ and as an adjunct to treat acute preterm labor. ${ }^{5}$ It has been shown to reduce the risk of recurrent preterm birth when used prophylactically but has not been thoroughly investigated as an adjunct to tocolytic drugs. Erny et $\mathrm{al}^{6}$ found that oral $\mathrm{P}$ reduced uterine activity, compared with placebo, in a randomized comparison in 57 women admitted with risk of preterm labor. Noblot et $\mathrm{al}^{5}$ found that the addition of micronized $\mathrm{P}$ to $\beta$-mimetic treatment reduced uterine

From the Department of

Pharmacodynamics and Biopharmacy, Faculty of Pharmacy, University of Szeged, Szeged, Hungary.

Received Feb. 14, 2007; revised Jun. 5, 2007; accepted Sep. 10, 2007.

Reprints: George Falkay, DSc, Department of Pharmacodynamics and Biopharmacy, University of Szeged, H-6720 Szeged, Eötvös u. 6, Hungary; falkay@pharm.u-szeged.hu.

0002-9378/\$34.00

(C) 2008 Mosby, Inc. All rights reserved. doi: 10.1016/j.ajog.2007.09.027 activity more quickly than $\beta$-mimetic treatment alone, but there was no effect on the prolongation of pregnancy.

It is known that $\mathrm{P}$ increases $\beta_{2}$-adrenergic receptor (AR) expression during pregnancy, ${ }^{7}$ and $\mathrm{P}$ can alter the effects of $\beta_{2}$-AR agonists on the pregnant myometrium. ${ }^{8}$ Gáspár et $\mathrm{al}^{9}$ demonstrated that in vivo $\mathrm{P}$ treatment can favorably affect the level of the $\beta_{2}$-ARs and also enhance the uterus-relaxing effect of terbutaline in vitro. Chanrachakul et $\mathrm{al}^{10}$ found that in vitro $\mathrm{P}$ increased the uterus-relaxing effect of ritodrine by reducing $50 \%$ of the maximal response, amplitude, and frequency of the myometrial contractions in the isolated human pregnant myometrium.

The efficacy of the gestagen- $\beta_{2}$-agonist combination has not been adequately investigated in vivo. In the present study, we sought an answer as to whether gestagen treatment increases the effects of $\beta_{2}$-mimetics in hormoneinduced preterm delivery in rats in vivo.

\section{Material And Methods Housing and handling of the animals}

The animals were treated according to the European Communities Council Directives (86/609/ECC) and the Hungar- ian Act for the Protection of Animals in Research (XXVIII.tv.32.\$). All experiments involving animal subjects were carried out with the approval of the Hungarian Ethical Committee for Animal Research (registration IV/1813-1/ 2002). Sprague-Dawley rats (Charles River Laboratories, Hungary) were kept at $22 \pm 3^{\circ} \mathrm{C}$; the relative humidity was $30-70 \%$ and the light/dark cycle was 12 hours/12 hours. They were maintained on a standard rodent pellet diet (Charles River Laboratories), with tap water available ad libitum.

\section{Mating of the animals}

Mature female (180-200 g) and male (240-260 g) Sprague-Dawley rats were mated in a special mating cage. Vaginal smears were taken from the female rats and a sperm search was performed under a microscope at a magnification of $\times 1200$. If the smear proved positive, the female rats were separated and were regarded as first-day pregnant animals.

\section{Induction of premature labor}

Preterm labor was induced according to Rechberger et al. ${ }^{11}$ Briefly, the animals were treated with mifepristone ( $3 \mathrm{mg}$ per $0.1 \mathrm{~mL})$ and prostaglandin $\mathrm{E}_{2}\left(\mathrm{PGE}_{2} ; 0.5\right.$ $\mathrm{mg}$ /animal) on day 19 of pregnancy, 
FIGURE 1

Time schedule of treatments and initiation of hormone-induced preterm birth

A

Conception

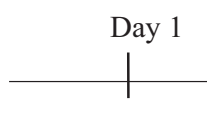

Group A:

Group B

Group C

Group D

Group E

Initiation of Treatments

Initiation of Induction

Day 15
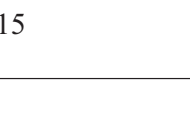

\section{Day 19}

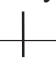

B
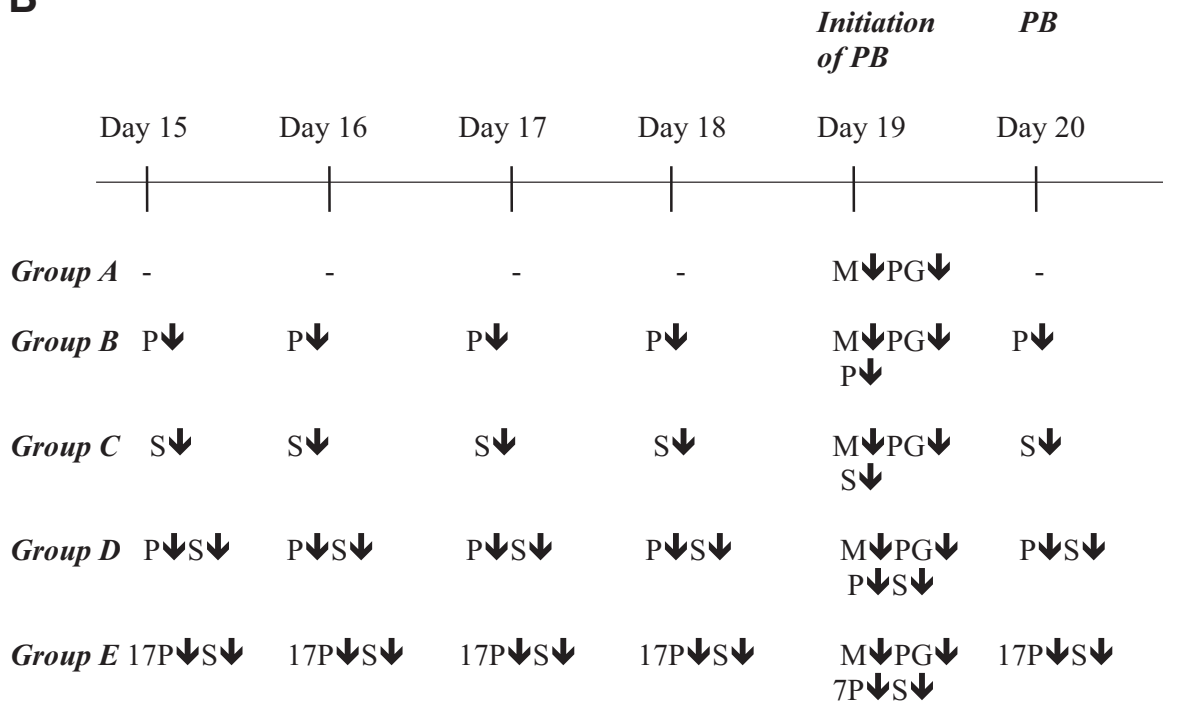

The time schedule of the treatments and the initiation of hormone-induced preterm birth in pregnant rats treated from day 15. A, Time schedule from conception to initiation of preterm birth. The salmeterol/gestagen treatments were started on day 15 in this case. When the salmeterol-gestagen treatments were initiated later in pregnancy (on day 16, 17, or 18), the days of conception and initiation of induction were the same, implicitly. B, Time schedule from the first treatment with salmeterol-gestagen to the preterm birth. When the salmeterol-gestagen treatments were initiated later in pregnancy (day 16, 17, or 18), the animals did not receive any treatments on the earlier days, implicitly. 17P, $17 \alpha$-hydroxyprogesterone caproate; $M$, mifepristone; $P$, progesterone; $P B$, preterm birth; $P G$, prostaglandin $\mathrm{E}_{2} ; S$, salmeterol.

Gálik. Gestagen treatment enhances tocolytic effect of salmeterol in hormone-induced preterm labor in rat. Am J Obstet Gynecol 2008.

which may approximately correlate to the gestation weeks 34-35 if we consider that the duration of pregnancy is 22 and 280 days in rat and human, respectively.
Mifepristone was suspended in olive oil and given as a subcutaneous injection at 9:00 A.M. At 4:00 P.M, $\mathrm{PGE}_{2}$ was applied intravaginally. The delivery time of the first fetus was noted as the duration in hours from the time of mifepristone administration.

\section{Treatments of the animals}

Salmeterol xinafoate (Sigma Aldrich, Budapest, Hungary) was dissolved in a 1:1 methanol-water mixture. Alzet osmotic pumps (model 2ml1; DURECT Corp, Cupertino, CA) loaded with salmeterol xinafoate solution or the vehicle was inserted subcutaneously into the back skin of rats on days 15-18 of pregnancy (which may correlate to gestation weeks 27-35 in humans) under isoflurane anesthesia (Burton's narcotic apparatus). The dose of salmeterol was 130 $\mu \mathrm{g} /$ day per animal. Pefloxacin was used in dose of $8 \mathrm{mg}$ per $0.1 \mathrm{~mL} / \mathrm{animal}$ to prevent subsequent infections.

P (Sigma Aldrich) or 17 $\alpha$-hydroxyprogesterone caproate (17P; donated by Richter Gedeon NyRt, Budapest, Hungary) was suspended in olive oil and was injected subcutaneously in a dose of $0.5 \mathrm{mg}$ per $0.1 \mathrm{~mL} /$ day from days of pump insertions to day 20 of pregnancy. The time schedule of the animal treatments is shown on Figure 1.

\section{Experimental design}

Group A was the control group, and group $B$ was treated with $P$, group $C$ with salmeterol, group D with the combination of salmeterol and $\mathrm{P}$, and group $\mathrm{E}$ with the combination of salmeterol and 17P. Eight rats were in each group. All the animals were operated on for osmotic minipump insertion and were treated with subcutaneous injections. The osmotic minipumps contained salmeterol or vehicle, and the subcutaneous injection contained gestagens or the vehicle.

The salmeterol/gestagen/vehicle treatments started on different days $(15,16$, 17 , or 18) of pregnancy, with the exception of the animals in group E, in which the treatment always started on pregnant day 15.

Statistical analysis was carried out with the analysis of variance Newman-Keuls test. 


\section{FIGURE 2 \\ Effects of $P$, salmeterol, and combined gestagen-salmeterol treatments started on gestation day 15 on hormone-induced preterm delivery}
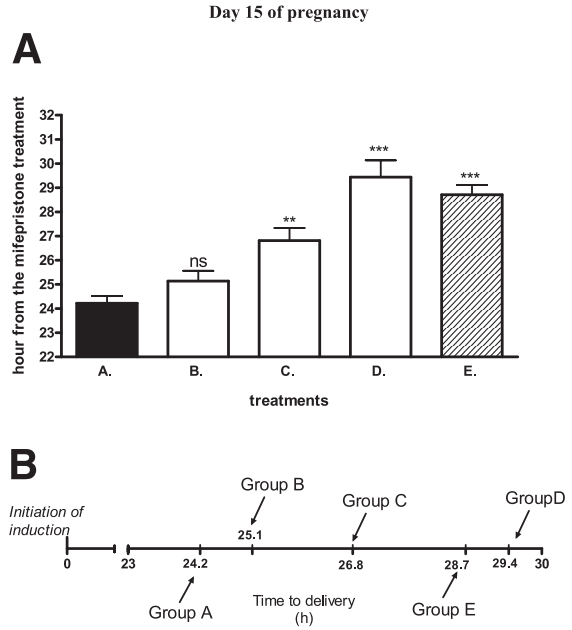

The effects of progesterone $(0.5 \mathrm{mg}$ per $0.1 \mathrm{~mL})$, salmeterol (130 $\mu \mathrm{g} /$ day), and combined gestagen-salmeterol treatments on hormone-induced preterm delivery in the rat $(n=8$ for each group). The treatments were started on gestation day 15. A, A, control group; B, P-treated; C, salmeterol-treated; $D$, salmeterol-P combination-treated; E, salmeterol-17 $\alpha$-hydroxyprogesterone caproate combination-treated animals. The bar graphs show means $\pm \mathrm{SEM}$. The effects were compared with the results on the control group. ns, not significant. Asterisk indicates $P$ $<.05$; double asterisks indicate $P<.01$; triple asterisks indicate $P<.001$. The difference in efficacy between the treatments reflected in groups $\mathrm{C}$ and $\mathrm{D}$ was significant $(P<.01)$. The group $E$ combination was as effective as the group $\mathrm{D}$ combination $(P>.05)$. B, Time to delivery from the initiation of preterm birth (mifepristone treatment). The longest delay was caused by the combination of salmeterol-progesterone (5.2 hours).

Gálik. Gestagen treatment enhances tocolytic effect of salmeterol in hormone-induced preterm labor in rat. Am J Obstet Gynecol 2008.

\section{RESUlTS}

In group A (control), preterm labor occurred within 24 hours after mifepristone treatment, at about 9:00 A.M. on pregnancy day 20 (which may correlate to the 36th week of pregnancy in humans).

Group B (P) treatment started on pregnancy day 15 and was not effective in delaying the hormone-induced preterm delivery. In contrast, in group C (salmeterol), the treatment was effective; premature birth was delayed by 2.4 hours. The group D (salmeterol-P combination) delayed labor by 5.2 hours (Figure 2).

The results were similar when the treatments started on days 16-18 of pregnancy (Figures 3-5). In each case, group $\mathrm{D}$ and group $\mathrm{E}$ (combined therapy) was more effective than group B and C (simple treatment). The difference in efficacy between groups $\mathrm{C}$ and $\mathrm{D}$ was most expressed for the treatment started on day 15 (Figure 2).

In group $\mathrm{E}$, the preterm birth-delaying effect of salmeterol-17P treatment was very similar to that of the salmeterol-P combination. The difference between the 2 combinations was not significant (Figure 2).

\section{Comment}

Chanrachakul et al ${ }^{10}$ investigated the effects of in vitro $\mathrm{P}$ and ritodrine on oxytocin-induced human myometrial contractility. They reported that $\mathrm{P}$ significantly enhances the relaxant effect of the $\beta_{2}$-mimetic by reducing both the amplitude and the frequency of the contractions. These previous results led us to test the efficacy of salmeterol-gestagens ( $\mathrm{P}$ and $17 \mathrm{P}$ ) treatment in hormone-induced preterm delivery in rat in vivo. We used the same in vivo $\mathrm{P}$ dose that had proved effective in increasing the effect of the $\beta_{2}$-agonist in our earlier study. ${ }^{9}$ An in vivo dose for the tocolytic effect of salmeterol was not available for the rat; we therefore chose the dose used by Moore et al. ${ }^{12}$ This dose was able to induce muscular growth in the rat, indicating the systemic effect of the drug. ${ }^{12}$

Interestingly, although delivery did result from the $\mathrm{P}$ antagonist mifepristone in combination with $\mathrm{PGE}_{2}$, the gestagen treatment did not prevent the hormoneinduced premature labor. Salmeterol treatment was effective in delaying preterm labor, and this effect was doubled by its combination with gestagens, independently of the first day of treatment: even 1 day of gestagen treatment before the administration of mifepristone and
FIGURE 3

Effects of $\mathrm{P}$, salmeterol, and
combined P-salmeterol
treatments started on gestation
day 16 on hormone-induced
preterm delivery

Day 16 of pregnancy

A

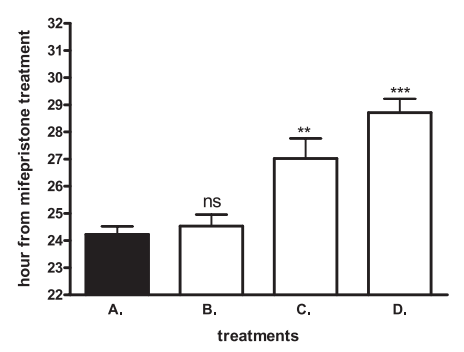

B

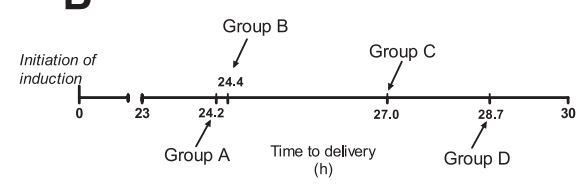

The effects of $P(0.5 \mathrm{mg}$ per $0.1 \mathrm{~mL})$, salmeterol $(130 \mu \mathrm{g} /$ day), and combined P-salmeterol treatments on hormone-induced preterm delivery in the rat ( $n=8$ for each group). The treatments were started on gestation day 16. A, A, control group; B, P-treated animals; C, salmeteroltreated animals; $D$, salmeterol-P combinationtreated animals. The bar graphs show means \pm SEM. The effects were compared with the results on the control group. ns, not significant. Asterisk indicates $p<.05$; double asterisks indicate $P<.01$; triple asterisks indicate $P<.001$. The difference in efficacy between the treatments reflected in groups $\mathrm{C}$ and $\mathrm{D}$ was significant $(P$ $<.05)$. B, Time to delivery from the initiation of preterm birth (mifepristone treatment). The longest delay was caused by the combination of salmeterol-progesterone (4.5 hours).

Gálik. Gestagen treatment enhances tocolytic effect of salmeterol in hormone-induced preterm labor in rat. Am J Obstet Gynecol 2008.

$\mathrm{PGE}_{2}$ potentiated the effect of salmeterol. This result means that the enhanced synergistic effect of gestagens can develop rapidly. The improved efficacy of the combination can very probably be explained by the gestagen-induced increases in the myometrial $\beta_{2}$-AR density and the amount of activated $\mathrm{G}$ proteins coupled to $\beta$-ARs, as found earlier. ${ }^{9}$

It should be emphasized that there are some limitations of our study. We at- 


\section{FIGURE 4}

\section{Effects of $P$, salmeterol, and combined P-salmeterol treatments started on gestation day 17 on hormone-induced preterm delivery}

Day 17 of pregnancy

A

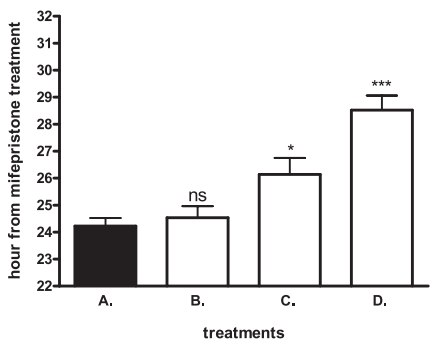

\section{B}

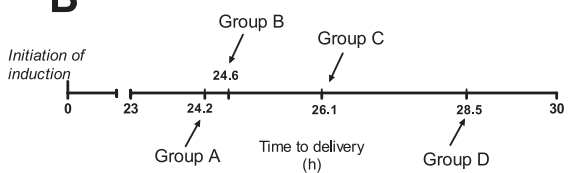

The effects of $P(0.5 \mathrm{mg}$ per $0.1 \mathrm{~mL})$, salmeterol $(130 \mu \mathrm{g} /$ day), and combined P-salmeterol treatments on hormone-induced preterm delivery in the rat ( $\mathrm{n}=8$ for each group). The treatments were started on gestation day 17. A, control group; B, P-treated animals; C, salmeteroltreated animals; D, salmeterol-P combinationtreated animals. The bar graphs show means \pm SEM. The effects were compared with the results on the control group. ns, not significant. Asterisk indicates $P<.05$; double asterisks indicate $P<.01$; triple asterisks indicate $P<.001$. The difference in efficacy between the treatments reflected in groups $\mathrm{C}$ and $\mathrm{D}$ was significant $(P$ $<.05$ ). B. Time to delivery from the initiation of preterm birth (mifepristone treatment). The longest delay was caused by the combination of salmeterol-P (4.3 hours).

Gálik. Gestagen treatment enhances tocolytic effect of salmeterol in hormone-induced preterm labor in rat. Am J Obstet Gynecol 2008

tempted to demonstrate the effects of these compounds on a lipopolysaccharide (LPS)-induced preterm labor model, which is widely accepted as an appropriate animal test for human preterm birth. Unfortunately, we have not been able to construct an LPS model with good reproducibility. The majority of the pregnant rats were not able to deliver the fetuses: frequent intrauterine deaths occurred, as described earlier. ${ }^{13}$
Terrone et $\mathrm{al}^{14}$ reported results on LPSinduced preterm birth with rats, but in those experiments the LPS-induced delivery occurred 92 hours after the initiation of the process and the live birth rate was only around $50 \%$. The LPS-induced delivery could be delayed by $26-29$ hours with parallel or preventive interleukin treatment. ${ }^{14}$

A comparison of the LPS- and the hormone-induced models clearly reveals that the process of LPS-induced delivery is slower, and therefore, there may be a greater chance of reaching a longer prolongation of the whole process than in the case of hormone-induced preterm birth, in which the process is drastic and has been completed within 24 hours. Accordingly, the more than 5-hour delay in the hormone-induced model should be regarded as a significant and promising effect of the combinations of salmeterol and the gestagen compounds.

Another weakness of this study is that the experiments do not provide any data about the prompt effect of the drugs in the onset of the hormone-induced preterm birth, but the investigation of a prompt effect is almost impossible in rats. The first visual sign of the onset of labor is vaginal bleeding. From this time on, we have a maximum of only 10-15 minutes (frequently much less) until the delivery of the first fetus. This short period is surely not enough for the absorption of drugs administered extravasally, whereas intravenous administration is not appropriate for the gestagens. Additionally, the osmotic minipump is not really suitable for fast treatment. Nevertheless, in spite of all these weaknesses, our study is the first in which an attempt is made to delay the antigestagen-prostaglandin-induced preterm birth in vivo.

The fact that the gestagens potentiate the uterus-relaxing effect of $\beta_{2}$-mimetics may yield a possibility for avoiding or diminishing the overuse of $\beta_{2}$-agonists and the pregnancy-induced desensitization of $\beta_{2}$-ARs. ${ }^{9,15,16}$

We conclude that a putative therapeutic combination of a $\beta_{2}$-AR agonist and a gestagen compound may enhance the efficacy of human tocolytic therapy. Although it is very difficult to transpose such a result from an animal study into human practice,
FIGURE 5

Effects of $\mathrm{P}$, salmeterol, and
combined P-salmeterol
treatments started on gestation
day 18 on hormone-induced
preterm delivery

Day 18 of pregnancy

A
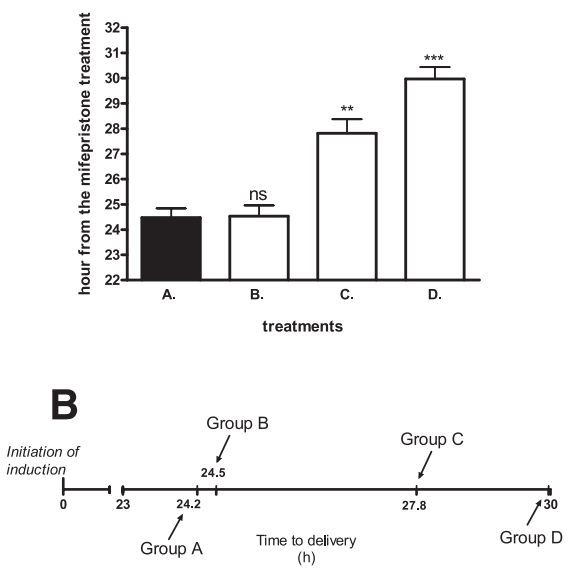

The effects of progesterone $(0.5 \mathrm{mg}$ per $0.1 \mathrm{~mL})$, salmeterol (130 $\mu \mathrm{g} / \mathrm{day})$, and combined P-salmeterol treatments on the hormone-induced preterm delivery in the rat $(\mathrm{n}=8$ for each group). The treatments were started on gestation day 18. A, A, control group; B, P-treated animals; C, salmeterol-treated animals; D, salmeterol-P combination-treated animals. The bar graphs show means \pm SEM. The effects were compared with the results on the control group. $n s$, not significant. Asterisk indicates $P<.05$; double asterisks indicate $P<.01$; triple asterisks indicate $P<.001$. The difference in efficacy between the treatments reflected in groups $C$ and $\mathrm{D}$ was significant $(P<.05)$. B, Time to delivery from the initiation of preterm birth (mifepristone treatment). The longest delay was caused by the combination of salmeterol-P (5.8 hours).

Gálik. Gestagen treatment enhances tocolytic effect of salmeterol in hormone-induced preterm labor in rat. Am J Obstet Gynecol 2008

we presume that the delay of more than 5 hours caused by the salmeterol-gestagen in rat preterm delivery is very promising for human trials. If we consider that both $\beta_{2^{-}}$ mimetics and gestagens are well known with regard to their pharmacokinetics and toxicity, the expected therapeutic risk of their combination is relatively low. In view of all the preclinical results and earlier experience with the drugs, we think that 
there is sufficient evidence indicative of the potentiation of the $\beta_{2}$-mimetic effect by gestagens in pregnant uterine relaxation. The time may have come to begin trials to clarify the effects of such a combination in human preterm birth.

\section{ACKNOWLEDGMENT}

Special thanks go to Anna Klukovits, PhD, and Renáta Minorics, PhD, for their contribution to the experimental work.

\section{REFERENCES}

1. Johnson JW, Austin KL, Jones GS. Efficacy of 17alpha-hydroxyprogesterone caproate in the prevention of premature labor. N Engl J Med 1975;293:675-80.

2. Keirse MJ. Progestogen administration in pregnancy may prevent preterm delivery. $\mathrm{Br} J$ Obstet Gynaecol 1990;97:149-54.

3. Meis PJ, Klebanoff M, Thorm E. Prevention of recurrent preterm delivery by 17-alpha hydroxyprogesterone caproate. N Engl J Med 2003;349:1299.

4. da Fonseca EB, Bittar RE, Carvalho MH. Prophylactic administration of progesterone by vaginal suppository to reduce the incidence of spontaneous preterm birth in women at increased risk: a randomized placebo-controlled, double-blind study. Am J Obstet Gynecol 2003;188:419-424.

5. Noblot G, Audra P, Darquent D. The use of micronized progesterone in the treatment of menace of preterm delivery. Eur J Obstet Gynecol Reprod Biol 1991;40:203-9.

6. Erny A, Piqne A, Prouvost C. The effects of oral administration of progesterone for premature labor. Am J Obstet Gynecol 1986; 154:525-9.

7. Roberts JM, Riemer RK, Bottari SP. Hormonal regulation myometrial adrenergic responses: the receptor and beyond. J Dev Physiol 1989;11:125-34.

8. Dowel RT, Forsberg AL, Kauer CD. Decreased ovarian blood flow may confound the tocolytic effect of ritodrine. Gynecol Obstet Invest 1994;37:168-71.

9. Gáspár R, Ducza E, Mihályi A. Pregnancyinduced decrease in the relaxant effect of terbutaline in the late-pregnant rat myometrium: role of G-protein activation and progesterone. Reproduction 2005;130:113-22.

10. Chanrachakul B, Pipkin FB, Warren AY. Progesterone enhanced the tocolytic effect of ritodrine in isolated pregnant human myometrium. Am J Obstet Gynecol 2005;192:458-63.
11. Rechberger T, Abramson SR, Woessner JF Jr. Onapristone and prostaglandin E2 induction of delivery in the rat in late pregnancy: a model for the analysis of cervical softening. Am J Obstet Gynecol 1996;175:719-23.

12. Moore NG, Pegg GG, Silence MN. Anabolic effects of the $\beta_{2}$-adrenoceptor agonist salmeterol are dependent on route of administration. Am J Physiol 1994;267:475-84.

13. Elovitz MA, Mrinalini C. Animal models of preterm birth. Trends Endocrinol Metab 2004;15:479-87.

14. Terrone DA, Rinehart BK, Granger JP. Interleukin-10 administration and bacterial endotoxin-induced preterm birth in a rat model. Obstet Gynecol 2001;98:476-80.

15. Berg G, Andersson RGG, Ryden G. Effects of selective $\beta$-adrenergic agonists in spontaneous contractions, cAMP levels and phosphodiesterase activity in myometrial strips from pregnant women treated with terbutaline. Gynecol Obstet Invest 1982;14: 56-64.

16. Berg G, Andersson RGG, Ryden G. In vitro study of phosphodiesterase-inhibiting drugs: compliment to $\beta$-sympathomimetic drug therapy in premature labor. Am J Obstet Gynecol 1983;145:802-6. 